\title{
Discussion on Case Teaching Method Based on Computational Thinking in Programming Teaching
}

\author{
Zhao Ni \\ Xi'an Technological University \\ Computer Science and Engineering College \\ Xi'an, China \\ e-mail: 651124115@qq.com
}

\begin{abstract}
Case teaching method based on computational thinking is introduced into the programming teaching. Take $\mathrm{C}++$ programming course as an example. Through the careful design of living cases, let students master how to combine computational thinking with programming method, and use computers to solve problems in life. In the cultivation of students' computational thinking ability, the students' innovative consciousness and comprehensive practical ability are also cultivated.
\end{abstract}

Keyword-Case Teaching; Computational Thinking; Process-oriented; Object-oriented

\section{INTRODUCTION}

In March 2006, Professor Jeannette M. Wing, Dean of the Department of Computing at Carnegie Mellon University in the United States, published and defined computational thinking in the Journal Communication of the ACM. She pointed out that computational thinking based on computational science was a series of thinking activities of computer science covered by problem solving, system design and human behavior understanding [1-2]. On July 20, 2010, nine universities of the first batch of China's "985 Project" Construction University Union published the Joint Statement of C9 League (C9) on Development Strategy of Basic Computer Teaching, which clearly pointed out that the cultivation of computational thinking ability was the core task of basic computer teaching [3]. In recent years, our school has generally begun to try curriculum reform based on computational thinking ability cultivation in the teaching of undergraduate computer related courses, aims to cultivate innovative talents skilled in computing concepts and methods, so as to adapt to the requirements of international competition.

\section{APPLICATION CASES OF COMPUTATIONAL THINKING IN PROGRAMMING TEACHING}

Programming Fundamentals is a compulsory basic computer course for science and engineering students in our school. The case teaching method based on computational thinking is introduced in teaching, to investigate the advantages and disadvantages of the traditional programming method and the programming method integrating computational thinking in an easy-to-understand approach, and cultivate students' innovative consciousness and comprehensive practice ability while cultivating the students' computational thinking ability.

\section{A. Application of computational thinking in process-oriented programming design}

C language, PASCAL, FORTRAN etc. are the process-oriented structured programming languages. $\mathrm{C}++$ is the improvement and extension of $\mathrm{C}$ language, which introduces the concepts and object-oriented thinking. Therefore, it is thought that $\mathrm{C}++$ is a mixed type language. It can use $\mathrm{C}$ language method, object-oriented method or two methods to program. The method of structured programming in $\mathrm{C}++$ is the realization of function of functions.

Case: computing thinking case of the function in life: the programming of class clean-up 
Analysis: Every student has been familiar with class clean-up since primary school. Generally it has two tasks of clean up the floor and cleaning the desk. Of which, cleaning the floor includes sweeping the floor and moping the floor. Each task can be realized by a function, which can simplify the complex problems. This is the process-oriented programming thinking "from the top to the bottom and gradual detailing”. See Figure 1.

Figure 1. Process-oriented Programming Case- Structure of Class Clean-up Program

Generally, several students responsible for cleaning the floor are assigned specifically. Some student moves stool, some student sweep the floor. The student mopping the floor also needs to put the stools on the desk. After the floor is mopped, such stools need to be put down. If the students responsible for these two tasks will re-put the stools or re-put down the stools for his/her own convenience. Such generates the redundancy. This does not only squander labor force but also delay time. So, in the function of sweeping the floor, use the function of mopping the floor after the floor is swept before the stool is not put down. When the function of mopping the floor is implemented, the student responsible for moving stools in function of sweeping floor may put down the stool, this is function embedding.

In daily life, after the floor is cleaned, then the desk is cleaned up. In order to tell the students responsible for mopping desk begin to work, the function of sweeping floor needs to give a result after the floor is cleaned, it is called returned value of function. Besides needing to know "who to do", "to whom", "what tool", the function of mopping the desk also needs to know whether the desk is cleaned. These data has formed required parameters implementing functions. From the angle of computing thinking, class clean-up programming process is given. See Chart 2.

Figure 2. Computing Thinking Case of Function Application - Design of Class Clean-up Program

Seen from Chart 2, during the process-oriented programming, data, object or operation are separated. Function will obtain data through parameter transfer and implement related operation. In this case, if programming this task further, use the main program to realize all functions of clean-up, then all programmers edit the function realizing some function. This is the application of separation of concerns in computational thinking. Practice proves that the complex problem is decomposed from the top to the bottom may have good begun.

\section{B. Application of computational thinking in object-oriented programming teaching}

"What is the world made of ?" Aiming at this problem, different person has different answer. Chemist thinks the world is made of molecule, atom, ion and other chemical substances; Artist thinks the world is made of different colors; taxonomist may think that the world is made of different types of material or things. Object oriented programming is to consider the problem at the angle of taxonomist. It tries to use the method describing things of the objective world to describe the problem solved by a program. It makes the software developer to use common thinking method that human being cognizes the world for software development.

During the object-oriented programming, objective things is regarded as the object with property and action, category is the common static and dynamic characteristics abstracting from the same objects. For example, "Human being" has the properties of height, weight, age, blood type and the behaviors of labor, upright walk, creating and using tool, etc. man is different from other type of animal. Each person has the property and behavior of human being, why does tiger, elephant not belong to person? Because they do not have the property of human being, for example, they cannot walk upright, cannot use tools etc. "Category" is only an abstract concept. We are the real objects of existed in "human being". Category can have relationship with outside world by a simple outer interface. The objects can communicate through information. The independence of programming modules and safety of data shall have the guarantee. The relationship between modules is easier. Through category's succeeding and multi-status can realize the reutilization of code, which greatly shortens the period of software development. 
Case: Category and object's computational thinking case: programming of personal bank account management)

Analysis: generally, one person may have several demand deposit accounts and one demand deposit account includes account number, balance, annual interest rate and etc. and it also includes displaying account information, settling of saving, withdrawal, and interests. From the angle of computational thinking, the designing process is shown in Figure 3.

Figure 3. Computational thinking case of category and object—Design of personal bank account management program

The essence of computational thinking is rational abstraction and efficient algorithms. Abstraction is the modeling and simulation of the physical world, and the change of the physical world is interpreted as a process of calculation. This is a process from concrete to general. For example, in Figure 3, the common features of the attributes (account number, balance, interest rate, etc.) and behaviors (display, deposit, withdrawal, settlement) of the accounts of different individuals in the real world are abstracted to the computer world, then there is the account class, and the class is instantiated to get the specific account object of an individual. Packaging contains two meanings, one is that all attributes and all methods of the object are combined together, to form an indivisible independent unit (i.e. object); on the other hand, information hiding, that is, to hide the internal details of an object as far as possible, to form an external barrier, only limited external interfaces are retained to contact with the external. When a user uses an object, it only needs to care about the operations that can be performed on that object, without caring about its internal details.

\section{CONCLUSION}

Computational thinking is one of the essential qualities for innovative talents to adapt to international competition [4-5]. The case teaching based on computational thinking relies on examples in life, effectively mobilizes the enthusiasm of students to learn programming, and facilitates the students to analyze problems with the method of computational thinking and study independently, and thus improve the comprehensive application ability in solving practical problems.

\section{REFERENCES}

[1] Jeannette M. Wing. "Computational Thinking", Communication of the ACM, NO.49(Mar.2006):33-35.

[2] Wing J M(2008), Computational Thinking and Thinking About Computing, J. Philosophical Transactions of the Royal Society. 366,3717-3725.

[3] Dong Rongsheng Joint Statement of C9 League (C9) on Development Strategy of Basic Computer Teaching calls for the transformation of education, Chinese University Teaching, 10th issue of 2010: 14-15.

[4] "CM/IEEE Computer Society Interim Review Task Force," Computer science curriculum 2008:An interim revision of CS 2001, accessed June 28, 2010, http://www.acm.org/education/curricula/.

[5] Dong Rongsheng Gu Tianlong(2009), Computational Thinking and Methodology of Computer, J. Computer Science. 36, 1, 1-4, 42.

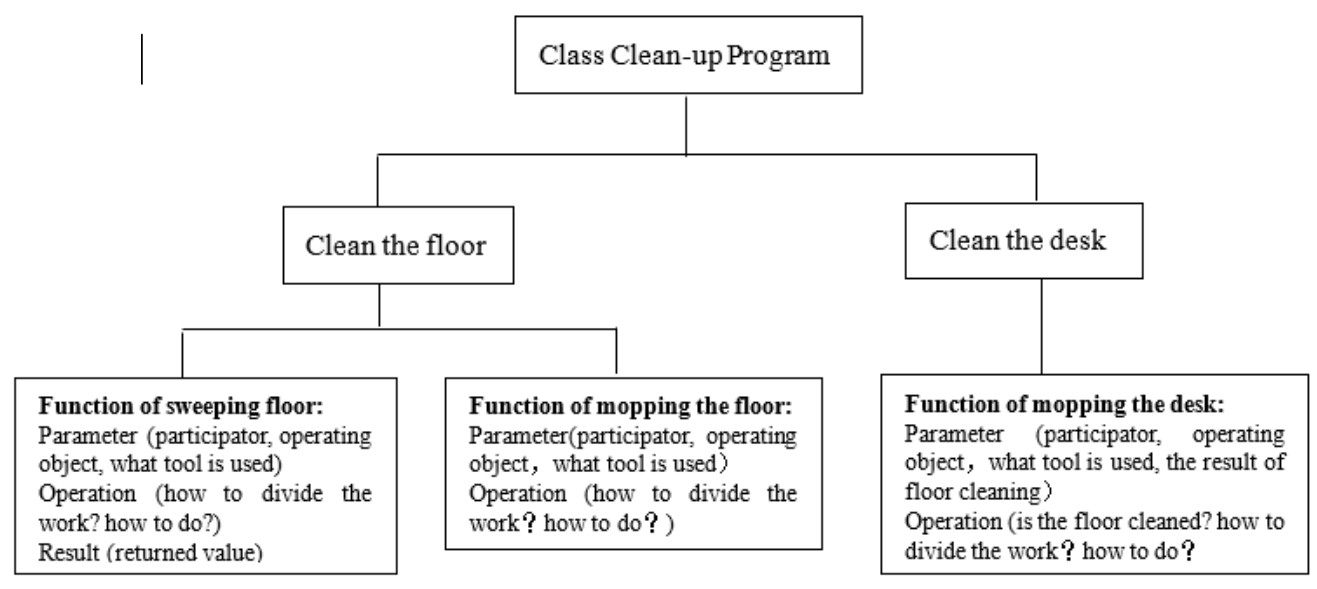

Figure 1. Process-oriented Programming Case- Structure of Class Clean-up Program 


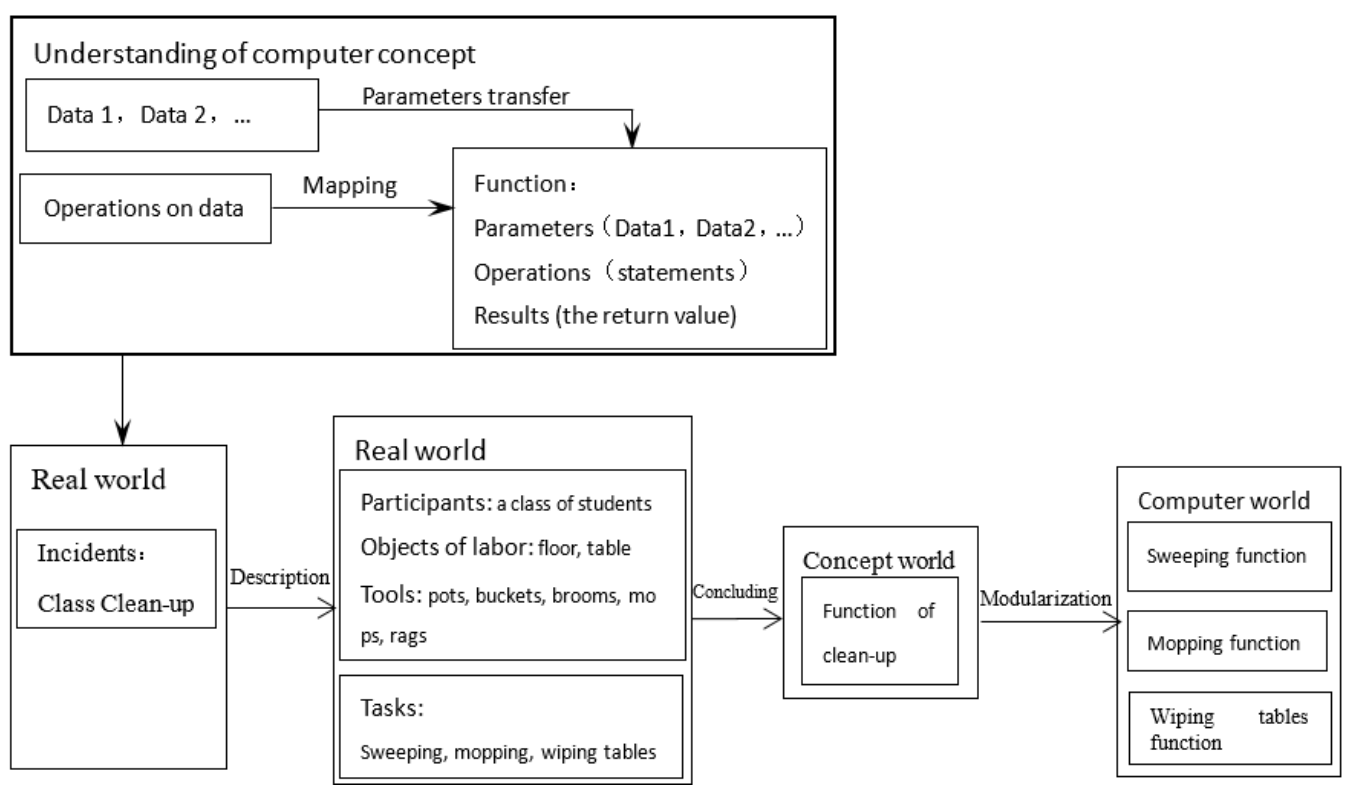

Figure 2. Computing Thinking Case of Function Application - Design of Class Clean-up Program

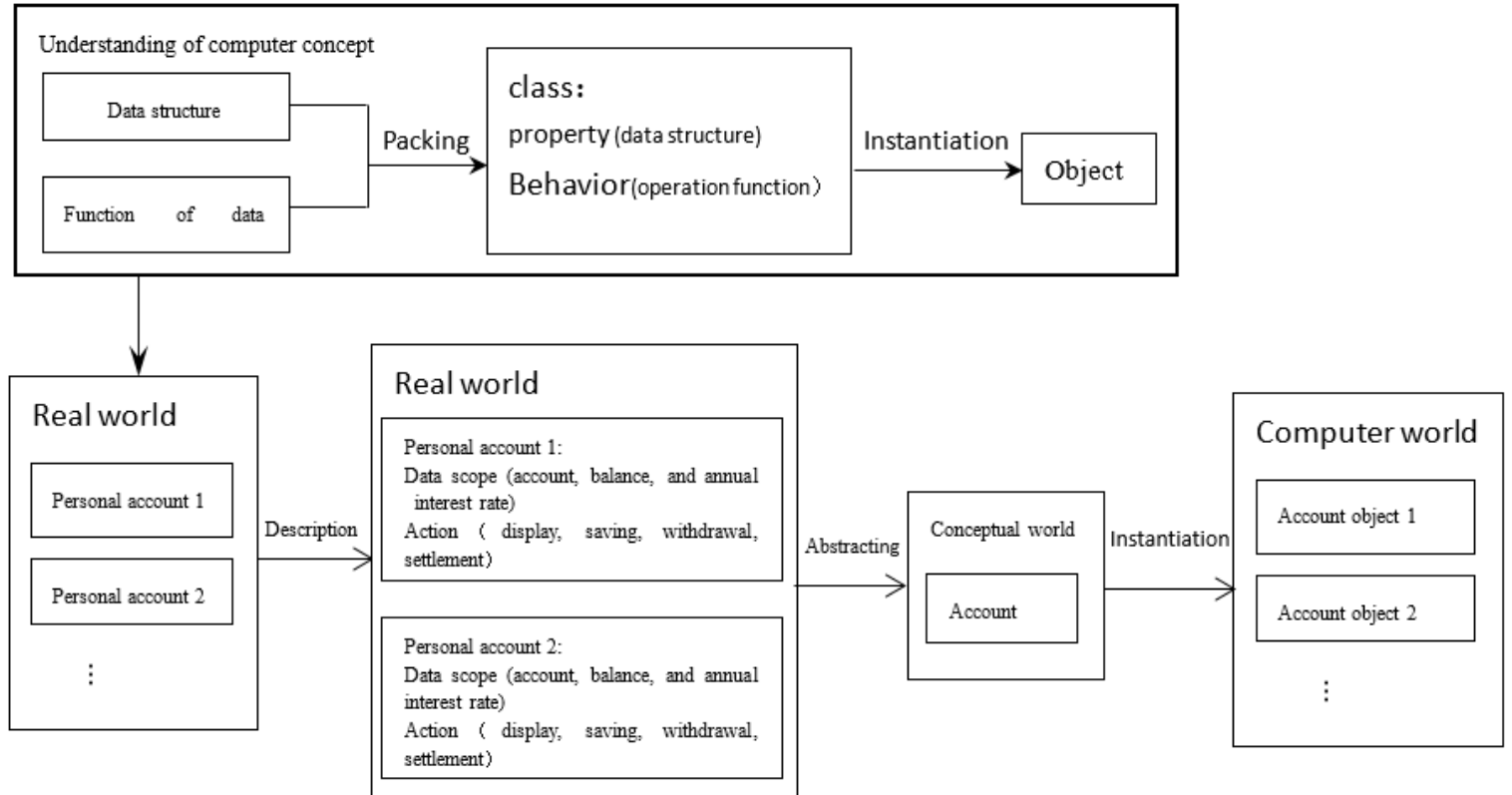

Figure 3. Computational thinking case of category and object—Design of personal bank account management program 